\title{
Role of estrogen receptor signaling in skeletal response to leptin in female ob/ob mice
}

\author{
Russell T Turner1,2, Kenneth A Philbrick', Amida F Kuah', Adam J Branscum³ and \\ Urszula T Iwaniec ${ }^{1,2}$
}

1Skeletal Biology Laboratory, School of Biological and Population Health Sciences, Oregon State University, Corvallis, Oregon, USA

${ }^{2}$ Center for Healthy Aging Research, Oregon State University, Corvallis, Oregon, USA

3Biostatistics Program, School of Biological and Population Health Sciences, Oregon State University, Corvallis, Oregon, USA

Correspondence should be addressed to $U \mathrm{~T}$ Iwaniec Email urszula.iwaniec@ oregonstate.edu

\begin{abstract}
Leptin, critical in regulation of energy metabolism, is also important for normal bone growth, maturation and turnover. Compared to wild type (WT) mice, bone mass is lower in leptin-deficient ob/ob mice. Osteopenia in growing ob/ob mice is due to decreased bone accrual, and is associated with reduced longitudinal bone growth, impaired cancellous bone maturation and increased marrow adipose tissue (MAT). However, leptin deficiency also results in gonadal dysfunction, disrupting production of gonadal hormones which regulate bone growth and turnover. The present study evaluated the role of increased estrogen in mediating the effects of leptin on bone in ob/ob mice. Three-month-old female ob/ob mice were randomized into one of the 3 groups: (1) $o b / o b+$ vehicle (veh), (2) ob/ob+leptin (leptin) or (3) ob/ob+leptin and the potent estrogen receptor antagonist ICI 182,780 (leptin $+\mathrm{ICI}$ ). Age-matched WT mice received vehicle. Leptin $(40 \mu \mathrm{g} / \mathrm{mouse}$, daily) and $\mathrm{ICl}(10 \mu \mathrm{g} / \mathrm{mouse}, 2 \times /$ week $)$ were administered by subcutaneous injection for 1 month and bone analyzed by X-ray absorptiometry, microcomputed tomography and static and dynamic histomorphometry. Uterine weight did not differ between ob/ob mice and ob/ob mice receiving leptin $+\mathrm{ICl}$, indicating that $\mathrm{ICl}$ successfully blocked the uterine response to leptin-induced increases in estrogen levels. Compared to leptin-treated ob/ob mice, ob/ob mice receiving leptin $+\mathrm{ICl}$ had lower uterine weight; did not differ in weight loss, MAT or bone formation rate; and had higher longitudinal bone growth rate and cancellous bone volume fraction. We conclude that increased estrogen signaling following leptin treatment is dispensable for the positive actions of leptin on bone and may attenuate leptin-induced bone growth.
\end{abstract}

Journal of Endocrinology (2017) 233, 357-367

\section{Introduction}

Leptin plays a role in regulating the rate of bone elongation, maturation of primary spongiosa, cortical and cancellous bone accrual, and cancellous bone turnover (Turner et al. 2013). Leptin-deficient $o b / o b$ mice and leptin receptor-
Key Words
- estrogen
- leptin
- bone formation and resorption
- skeletal biology
- marrow adipose tissue 
plates of $o b / o b$ mice are abnormal due, in part, to poorly organized collagen fibril arrangement (Kishida et al. 2005). The pathological manifestations in growth plate are associated with decreased type X collagen expression, increased chondrocyte apoptosis and premature mineralization (Kishida et al. 2005), suggesting that leptin modulates events associated with terminal differentiation of chondrocytes. Importantly, the defects in growth plate and bone microarchitecture are largely reversed in growing $o b / o b$ mice following administration of leptin (Kume et al. 2002, Maor et al. 2002, Kishida et al. 2005).

Osteoblast and osteoclast differentiation and/or function are also impaired in leptin signaling-deficient $o b / o b$ and $d b / d b$ mice (Turner et al. 2013). The lower bone formation generally reported in these mice is primarily due to reduced osteoblast number, although reduced osteoblast activity has also been noted. The dramatic increase in bone marrow adipose tissue (MAT) in long bones of leptin signaling-deficient mice suggests that leptin regulates bone marrow mesenchymal stem cell lineage decision; in the absence of leptin there is a net increase in marrow adipocytes and a decrease in osteoblasts. In contrast to a reduction in osteoblast perimeter, osteoclast perimeter is either normal or increased in $o b / o b$ and $d b /$ $d b$ mice (Turner et al. 2013). However, bone resorption is reduced, implicating impaired osteoclast activity. The osteoclast defect in these mice contributes to growth plate abnormalities and development of mild osteopetrosis: the pathological retention of calcified cartilage into adulthood in bone in $o b / o b$ and $d b / d b$ mice likely contributes to the reduced bone quality noted in these animals (Jing et al. 2016).

Although absence of leptin signaling is ultimately responsible for the skeletal abnormalities in $o b / o b$ and $d b /$ $d b$ mice, leptin is a pleiotropic hormone, impacting many physiological systems, including energy partitioning, thermogenesis, immune regulation, and gonadal function, each of which could independently influence bone metabolism (Mantzoros et al. 2011). Leptin is required for the release of gonadotropin-releasing hormone $(\mathrm{GnRH})$ from the pituitary and, as a consequence, female $o b / o b$ mice have greatly reduced estrogen levels and exhibit low uterine weight (Barash et al. 1996). GnRH-dependent estrogen synthesis and release play an important role in regulating bone elongation, accrual and turnover, and growing estrogen-deficient rodents exhibit skeletal abnormalities, including accelerated bone growth, increased bone turnover and cancellous bone loss (Turner et al. 1994, Burguera et al. 2001).
As mentioned, administration of leptin to $o b / o b$ mice reverses many, if not all, of the skeletal abnormalities associated with leptin deficiency (Hamrick et al. 2005, Kishida et al. 2005, Iwaniec et al. 2007, Bartell et al. 2011). However, leptin administration to $o b / o b$ mice also restores gonadal function (Barash et al. 1996) and in WT mice accelerates the onset of puberty (Ahima et al. 1997). Thus, it is possible that estrogen deficiency contributes to the skeletal phenotype observed in leptin signalingdeficient rodents and restoration of estrogen receptor signaling following leptin administration may influence the physiological response of $o b / o b$ mice to leptin. This possibility is consistent with the results of a recent leptin dose response study conducted in $o b / o b$ mice (Philbrick et al. 2017). Specifically, a pronounced dosedependent stimulatory effect of leptin on bone accrual plateaued at a dose rate that increased uterine weight (an index of estrogen levels). Therefore, the current study was designed to determine the precise role of estrogen signaling in the skeletal response to leptin. This was accomplished by administering leptin sc to $o b / o b$ mice in the presence or absence of the potent estrogen receptor antagonist ICI 182,780 (ICI) (Wakeling \& Bowler 1992). Treatment with ICI replicates the uterine and skeletal responses to ovariectomy (ovx) in rodents, and thus its administration to leptin-treated $o b / o b$ mice should prevent actions mediated through increased estrogen levels (Sibonga et al. 1998).

\section{Materials and methods}

\section{Experimental design}

One-month-old $o b / o b$ and WT mice were purchased from Jackson Laboratory and maintained until 3 months of age. The $o b / o b$ mice were then randomized by weight into one of 3 treatment groups: (1) ob/ob+vehicle (veh) $(n=5)$, (2) $o b / o b+l e p t i n$ (leptin) $(n=8)$ or (3) $o b / o b+l e p t i n+I C I$ $($ leptin $+\mathrm{ICI})(n=8)$. A group of WT mice (WT) $(n=9)$ received vehicle. Recombinant mouse leptin (CYT-351, Prospec Bio, Rehovot, Israel) was administered once daily by subcutaneous (s.c.) injection at a dose of $40 \mu \mathrm{g} / \mathrm{mouse} /$ day in $0.1 \mathrm{~mL}$ phosphate buffered saline (vehicle). ICI was administered $2 \times /$ week by sc injection at a dose of $10 \mu \mathrm{g} /$ mouse in $0.1 \mathrm{~mL}$ extra virgin olive oil. Fluorochromes were administered at 9 days (declomycin, $15 \mathrm{mg} / \mathrm{kg}$; Sigma Chemical), 4 days (calcein, $15 \mathrm{mg} / \mathrm{kg}$; Sigma Chemical) and 1 day (calcein) prior to necropsy to label mineralizing bone. Food (Teklad 8604, Harlen Laboratories, Indianapolis, IN,

Published by Bioscientifica Ltd. 
USA) and water were provided ad libitum to all animals. Body weight was recorded daily. Food intake was also recorded daily, except for days 12-14, 19-20 and 26-28 when it was averaged over a 2-3 day interval. The mice were maintained at room temperature $\left(22^{\circ} \mathrm{C}\right)$ and singly housed on a $12 \mathrm{~h}$ light- $12 \mathrm{~h}$ darkness cycle for the duration of study. For tissue collection, mice were anesthetized using isoflurane and killed by cardiac exsanguination followed by decapitation. Uteri and abdominal white adipose tissue (WAT) were excised and weighed. Femora and 5th lumbar vertebrae were removed, fixed for $24 \mathrm{~h}$ in $10 \%$ buffered formalin and stored in $70 \%$ ethanol for dual energy absorptiometry (DXA), microcomputed tomography $(\mu \mathrm{CT})$ and histomorphometric analyses. The experimental protocol was approved by the Institutional Animal Care and Use Committee in accordance with the NIH Guide for the Care and Use of Laboratory Animals.

\section{Densitometry}

Total femur bone mineral content (BMC, g), bone area $(\mathrm{cm} 2)$ and bone mineral density (BMD, $\mathrm{g} / \mathrm{cm} 2)$ were measured using DXA (Piximus 2, Lunar Corporation, Madison, WI, USA).

\section{Microcomputed tomography}

Microcomputed tomography was used for nondestructive 3-dimensional evaluation of bone volume and architecture. Femora and lumbar vertebrae were scanned in $70 \%$ ethanol using a Scanco $\mu \mathrm{CT} 40$ scanner (Scanco Medical AG, Bassersdorf, Switzerland) at a voxel size of $12 \times 12 \times 12 \mu \mathrm{m}\left(55 \mathrm{kV}_{\mathrm{p}} \mathrm{X}\right.$-ray voltage, $145 \mu \mathrm{A}$ intensity and $200 \mathrm{~ms}$ integration time). Filtering parameters sigma and support were set to 0.8 and 1, respectively. Voxels, having a threshold $\geq 245$ (0-1000), were used to distinguish bone from non-bone. Total femur mineralized tissue volume (cancellous + cortical bone) was evaluated. This was followed by site-specific evaluation of cortical bone in the midshaft femur and cancellous bone in the distal femur metaphysis and epiphysis. For the femoral midshaft, 20 slices $(0.24 \mathrm{~mm})$ of bone were evaluated and total crosssectional tissue volume (cortical and marrow volume, $\left.\mathrm{mm}^{3}\right)$, cortical volume $\left(\mathrm{mm}^{3}\right)$, marrow volume $\left(\mathrm{mm}^{3}\right)$, cortical thickness $(\mu \mathrm{m})$ and polar moment of inertia $\left(\mathrm{mm}^{4}\right.$, an index of bone strength in torsion) were measured. For the femoral metaphysis, 42 slices $(0.50 \mathrm{~mm})$ of cancellous bone were measured 45 slices $(0.54 \mathrm{~mm})$ proximal to the growth plate boundary. For the femoral epiphysis, the entire cancellous compartment ( $33 \pm 1$ slices) between the distal epiphyseal growth plate and distal femoral cortical shell was measured. $\mu \mathrm{CT}$ analysis of lumbar vertebrae was performed on cancellous bone within the vertebral body, between the cranial and caudal growth plates. Irregular manual contouring a few voxels interior to the endocortical surface was used to delineate cancellous from cortical bone. Direct cancellous bone measurements in the distal femur metaphysis and epiphysis and in lumbar vertebra included cancellous bone volume fraction (bone volume/tissue volume, \%), trabecular thickness $(\mu \mathrm{m})$, trabecular number $(/ \mathrm{mm})$, and trabecular separation $(\mu \mathrm{m})$.

\section{Histomorphometry}

Distal femora were dehydrated in a graded series of ethanol and xylene, and embedded undecalcified in modified methyl methacrylate as described (Iwaniec et al. 2008). Coronal sections ( $4 \mu \mathrm{m}$ thick) were cut with a vertical bed microtome (Leica 2065) and affixed to gel coated slides. One section per animal was stained for tartrate resistant acid phosphatase and counter stained with toluidine blue and used for cell-based measurements. A second section was left unstained for dynamic histomorphometry. Histomorphometric data were collected with a $20 x$ objective using the OsteoMeasure System (OsteoMetrics, Inc., Atlanta, GA, USA). The sampling site for the distal femoral metaphysis was located $0.25-1.25 \mathrm{~mm}$ proximal to the growth plate and $0.1 \mathrm{~mm}$ from cortical bone.

Cell-based measurements included osteoblast perimeter (osteoblast perimeter/bone perimeter, \%), osteoclast perimeter (osteoclast perimeter/bone perimeter, $\%)$, marrow adiposity (adipocyte area/tissue area, \%), adipocyte density (number of adipocytes/tissue area, \#/ $\mathrm{mm}^{2}$ ) and adipocyte size $\left(\mu \mathrm{m}^{2}\right)$. Osteoblasts, osteoclasts and adipocytes were identified as previously described (Iwaniec et al. 2016). Fluorochrome-based measurements of bone formation included mineralizing perimeter (mineralizing perimeter/bone perimeter: cancellous bone perimeter covered with double plus half single label normalized to bone perimeter, \%), mineral apposition rate (the mean distance between two fluorochrome markers that comprise each double label divided by the 3-day interlabel interval, $\mu \mathrm{m} /$ day), and bone formation rate adjusted for bone perimeter (bone formation rate/ bone perimeter: calculated by multiplying mineralizing perimeter by mineral apposition rate normalized to bone perimeter, $\left.\mu \mathrm{m}^{2} / \mu \mathrm{m} / \mathrm{year}\right)$. In addition, longitudinal growth rate was determined as the mean distance http://joe.endocrinology-journals.org DOI: $10.1530 / J O E-17-0103$ (c) 2017 Society for Endocrinology Printed in Great Britain
Published by Bioscientifica Ltd 
from the declomycin label to the mineralizing growth plate cartilage divided by the 9-day interval from label administration to sacrifice. All bone histomorphometric data are reported using standard 2-dimensional nomenclature (Dempster et al. 2013).

\section{Statistics}

Longitudinal data on body weight and food intake were analyzed using multivariate linear regression models with separate linear (body weight) or constant (food intake) time trends across groups. Candidate covariance models included independence, compound symmetric with and without equal variance across time and group, autoregressive of order 1, and moving average of order 1. Model selection was based on the Bayesian information criterion.

The principal goal of the analyses of tissues harvested at necropsy was to determine whether combination treatment (leptin +ICI) differed from leptin treatment. To accomplish this goal, mean responses of individual variables were compared for WT, vehicle, leptin and leptin+ICI mice using one-way analysis of variance, with Dunnett's used to adjust for making multiple comparisons to the leptin + ICI group. The Kruskal-Wallis nonparametric test was used when only the normality assumption was violated, and a modified $F$-test was used when the assumption of equal variance was violated

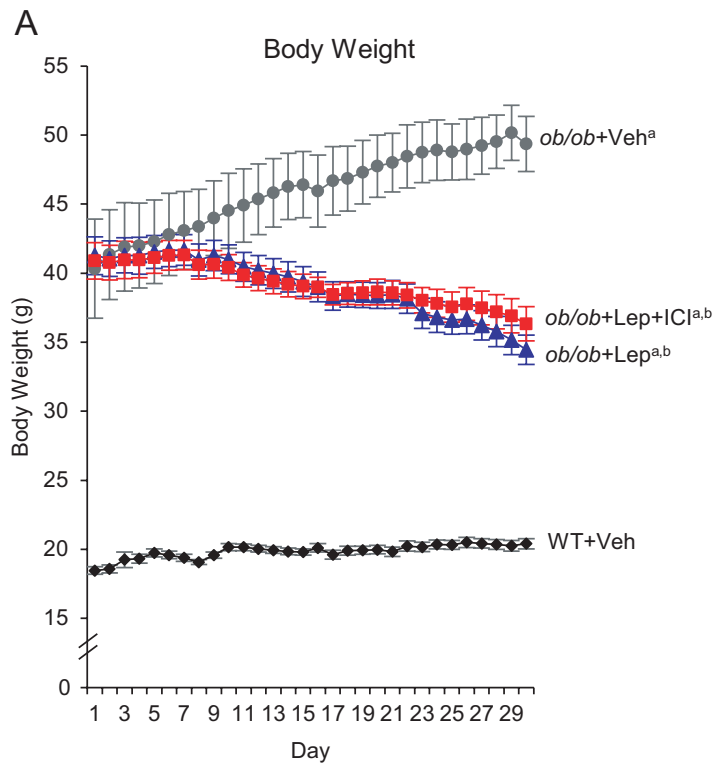

(Welch 1951); in these cases, the Wilcoxon-MannWhitney test or Welch's two-sample t-test was used for pairwise comparisons and the Holm procedure was used to adjust for multiple comparisons (Holm 1979). The required conditions for valid use of Gaussian analysis of variance models were assessed using Levene's test for homogeneity of variance, plots of residuals versus fitted values, normal quantile plots, and the AndersonDarling test of normality. Data analysis was performed using R version 3.3.2 (R Core Team 2015). Differences were considered significant at $P \leq 0.05$. All data are expressed as mean \pm s.E.

\section{Results}

The effects of leptin deficiency and treatment with leptin and leptin + ICI on body weight and food consumption in $o b / o b$ mice are shown in Fig. $1 \mathrm{~A}$ and B, respectively. Vehicle-treated $o b / o b$ mice weighed more and consumed more food than WT mice throughout the 4-week study. A progressive decrease in weight was observed in leptintreated mice but weight remained higher than in WT mice for the duration of treatment. Food consumption decreased in leptin-treated and leptin + ICI treated $o b / o b$ mice during the initial week of treatment. Mice treated with leptin + ICI did not differ from leptin-treated mice in body weight or food intake.

B

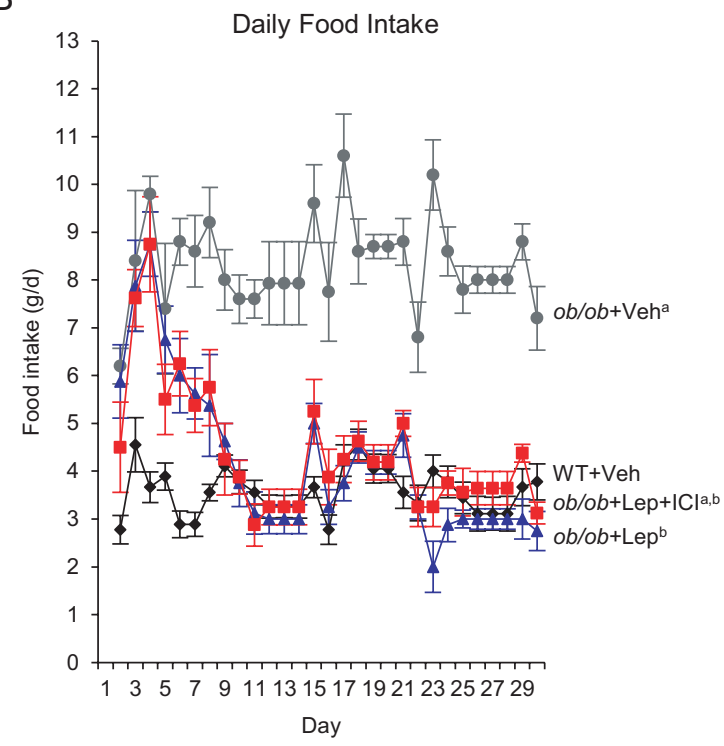

\section{Figure 1}

Effects of 1 month of daily sc leptin injection ( $40 \mu \mathrm{g} /$ mouse/day) in the presence or absence of the potent estrogen receptor antagonist ICI 182,780 (ICI)

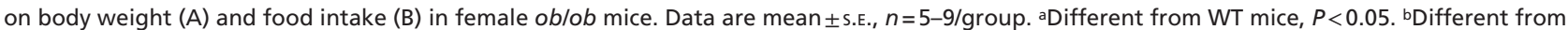
vehicle-treated ob/ob mice, $P<0.05$. 
A Abdominal WAT Weight
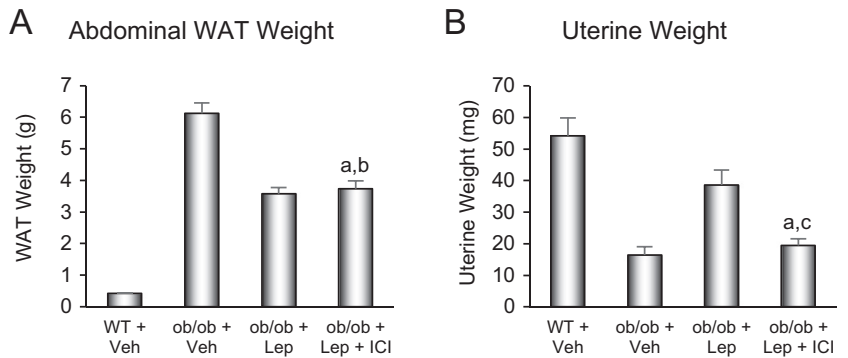

Figure 2

Effects of 1 month of daily sc leptin injection $(40 \mu \mathrm{g} /$ mouse/day) in the presence or absence of the potent estrogen receptor antagonist ICI 182,780 (ICI) on abdominal white adipose tissue (WAT) weight (A) and uterine weight (B) in female ob/ob mice. Data are mean \pm s.E., $n=5-9 /$ group. aLeptin $+\mathrm{ICl}$ treated ob/ob mice different from vehicle-treated WT mice, $P<0.05$; bleptin $+\mathrm{ICl}$ treated ob/ob mice different from vehicletreated ob/ob mice, $P<0.05$; cleptin $+\mathrm{ICl}$ treated ob/ob mice different from leptin-treated ob/ob mice, $P<0.05$.

The effects of treatment on abdominal WAT weight and uterine weight in $o b / o b$ mice are shown in Fig. 2A and $\mathrm{B}$, respectively. WAT weight in leptin+ICI treated mice was higher than in WT mice, lower than in vehicletreated mice but did not differ from leptin-treated mice.
In contrast, uterine weight in leptin + ICI treated mice was lower than in WT mice, did not differ from vehicle-treated mice and was lower than in leptin-treated mice.

The effects of treatment on femur DXA measurements, and microcomputed tomography measurements of cortical bone architecture in the midshaft femur, and cancellous bone architecture in the distal femur metaphysis and epiphysis in $o b / o b$ mice are shown in Table 1. Leptin+ICI treated mice did not differ from WT mice in total femur BMC, bone area, BMD or bone volume. Femur length and cortical thickness were lower in leptin + ICI treated mice compared to WT mice while cross-sectional bone volume, marrow volume and polar moment of inertia were higher. Bone volume fraction in distal femur metaphysis and epiphysis was higher and trabecular spacing lower in the leptin + ICI treated mice compared to WT mice and this was due to higher trabecular number and thickness in the metaphysis and higher trabecular number in the epiphysis. Leptin + ICI treated mice had longer femurs and higher BMC and BMD than vehicle-treated mice. Similarly, cortical volume, thickness and polar moment of inertia were

Table 1 Effects of 1 month of daily sc leptin injection ( $40 \mu \mathrm{g} / \mathrm{mouse} / \mathrm{day})$ in the presence or absence of the estrogen receptor antagonist ICI 182,780 (ICI) on femur bone mineral content and density and on cortical bone architecture in midshaft femur, and cancellous bone architecture in distal femur metaphysis and epiphysis in female ob/ob mice.

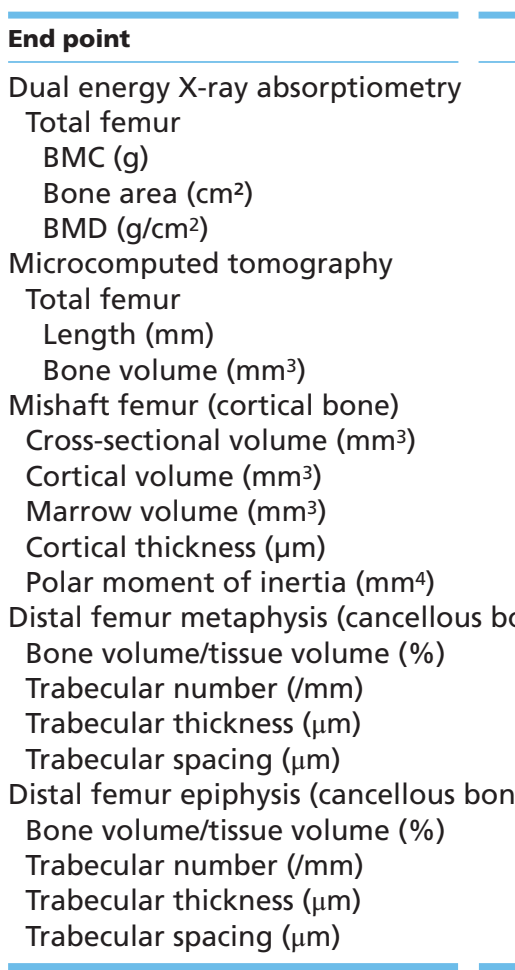

WT + Veh


$0.019 \pm 0.000$
$0.40 \pm 0.01$
$0.047 \pm 0.001$

ob/ob+Veh


$0.016 \pm 0.001$
$0.38 \pm 0.01$
$0.041 \pm 0.001$

$\begin{array}{cc}15.2 \pm 0.1 & 13.5 \pm 0.2 \\ 16.2 \pm 0.2 & 13.5 \pm 0.5 \\ & \\ 0.34 \pm 0.00 & 0.38 \pm 0.00 \\ 0.16 \pm 0.00 & 0.14 \pm 0.00 \\ 0.19 \pm 0.00 & 0.24 \pm 0.01 \\ 183 \pm 3 & 151 \pm 3 \\ 0.29 \pm 0.01 & 0.30 \pm 0.01\end{array}$

ne)

$4.4 \pm 0.4$

$3.8 \pm 0.1$

$40 \pm 1$

$273 \pm 5$ ne)

$25.9 \pm 0.5$

$5.1 \pm 0.2$

$61 \pm 1$

$200 \pm 5$

ob/ob + Lep

$0.017 \pm 0.000$
$0.40 \pm 0.01$
$0.044 \pm 0.000$

$14.0 \pm 0.1$

$15.1 \pm 0.3$

$0.38 \pm 0.01$

$0.16 \pm 0.00$

$0.23 \pm 0.01$

$167 \pm 3$

$0.34 \pm 0.01$

\begin{tabular}{c}
$6.6 \pm 1.1$ \\
$4.0 \pm 0.2$ \\
$42 \pm 2$ \\
$261 \pm 15$ \\
$26.5 \pm 0.3$ \\
$7.4 \pm 0.4$ \\
$50 \pm 0$ \\
$136 \pm 4$ \\
\hline
\end{tabular}

ob/ob + Lep $+I C l$

$0.019 \pm 0.001 b$
$0.41 \pm 0.01$
$0.046 \pm 0.001 b$

$14.0 \pm 0.1 \mathrm{ab}$

$15.6 \pm 0.3^{b}$

$0.40 \pm 0.01^{a}$

$0.16 \pm 0.00^{b}$

$0.24 \pm 0.01^{a}$

$164 \pm 2^{\mathrm{ab}}$

$0.35 \pm 0.01 \mathrm{ab}$
$7.9 \pm 0.3^{\mathrm{ac}}$

$4.1 \pm 0.04$ ac

$43 \pm 1^{a}$

$257 \pm 4^{\text {ac }}$

$31.4 \pm 0.6^{\mathrm{ab}}$

$6.6 \pm 0.2^{\mathrm{ab}}$

$60 \pm 1 \mathrm{~b}$

$148 \pm 4.2^{\mathrm{a}}$
ANOVA $\boldsymbol{P}$ value

0.0011

0.1000

0.0010

0.0000

0.0000

0.0000

0.0002

0.0000

0.0000

0.0004

0.0003

0.0046

0.0431

0.0293

0.0001

0.0000

0.0000

0.0000

Data are mean \pm S.E., $n=5-9 /$ group.

aLeptin + ICl treated ob/ob mice different from vehicle-treated WT mice, $P \leq 0.05$; bleptin + ICl treated ob/ob mice different from vehicle-treated $o b / o b$ mice, $P \leq 0.05$; cleptin $+\mathrm{ICl}$ treated ob/ob mice different from leptin-treated ob/ob mice, $P \leq 0.05$.

http://joe.endocrinology-journals.org

DOI: $10.1530 / \mathrm{JOE}-17-0103$ (c) 2017 Society for Endocrinology Printed in Great Britain
Published by Bioscientifica Ltd 
Table 2 Effects of 1 month of daily sc leptin injection $(40 \mu \mathrm{g} / \mathrm{mouse} /$ day) in the presence or absence of the estrogen receptor antagonist ICI 182,780 (ICI) on cancellous bone architecture in lumbar vertebra in female ob/ob mice.

\begin{tabular}{|c|c|c|c|c|c|}
\hline End point & WT + Veh & ob/ob+Veh & ob/ob+Lep & $o b / o b+L e p+I C I$ & ANOVA $P$ value \\
\hline Bone volume/tissue volume (\%) & $14.5 \pm 0.5$ & $24.4 \pm 1.2$ & $20.9 \pm 0.9$ & $20.1 \pm 1.4^{\mathrm{ab}}$ & 0.0000 \\
\hline Trabecular number (/mm) & $4.0 \pm 0.1$ & $5.6 \pm 0.1$ & $5.2 \pm 0.2$ & $5.4 \pm 0.1^{a}$ & 0.0000 \\
\hline Trabecular thickness $(\mu \mathrm{m})$ & $43 \pm 0$ & $44 \pm 1$ & $44 \pm 1$ & $43 \pm 1$ & 0.4650 \\
\hline Trabecular spacing $(\mu \mathrm{m})$ & $255 \pm 8$ & $175 \pm 5$ & $189 \pm 6$ & $184 \pm 3.4^{a}$ & 0.0000 \\
\hline
\end{tabular}

Data are mean \pm S.E., $n=5-9 /$ group

aLeptin $+\mathrm{ICl}$ treated $o b / o b$ mice different from vehicle-treated WT mice, $P \leq 0.05$; bleptin $+\mathrm{ICI}$ treated ob/ob mice different from vehicle-treated ob/ob mice, $P \leq 0.05$.

higher in the leptin+ICI treated mice. Bone volume fraction did not differ between leptin + ICI treated and vehicle-treated mice in the metaphysis but was higher in the leptin+ICI treated mice in the epiphysis. The latter was associated with lower trabecular number and higher trabecular thickness in the leptin+ICI treated mice.
Leptin + ICI treated mice did not differ from leptin-treated mice in femur length, femur bone volume or cortical bone architecture. However, the two groups differed in cancellous bone architecture; leptin+ICI treated mice had higher cancellous bone volume fraction in the metaphysis which was associated with higher trabecular
A Longitudinal Growh Rate

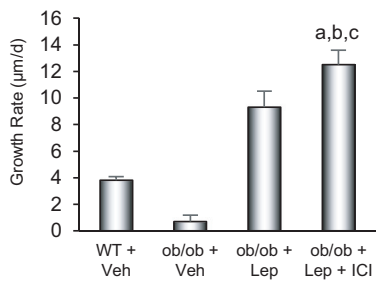

E

Osteoblast Perimeter

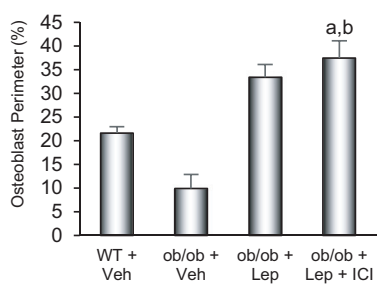

I

Adipocyte Size

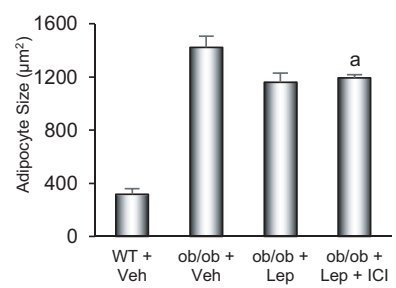

B

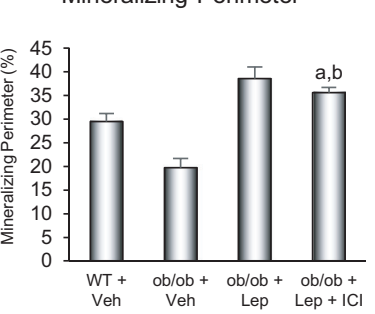

F

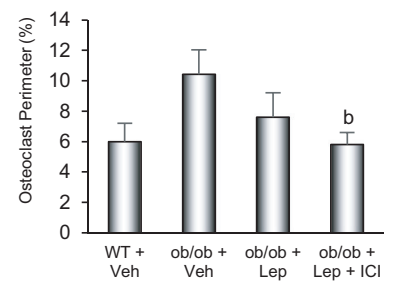

C

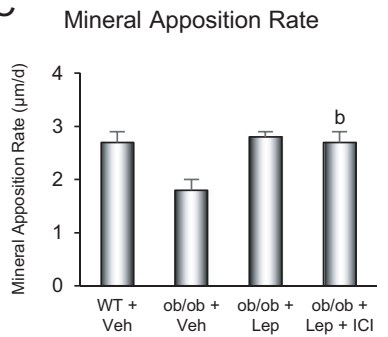

G

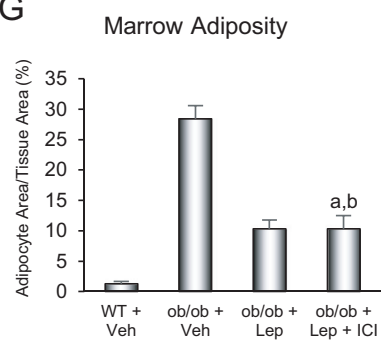

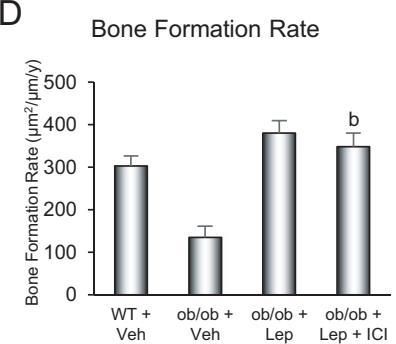

$\mathrm{H}$
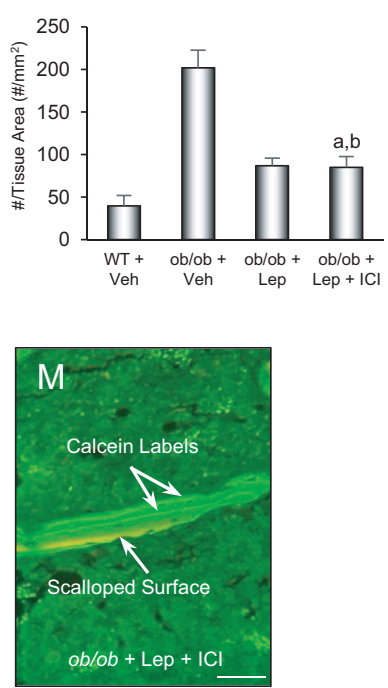

Figure 3

Effects of 1 month of daily sc leptin injection $(40 \mu \mathrm{g} /$ mouse/day) in the presence or absence of the potent estrogen receptor antagonist ICI 182,780 (ICI) on longitudinal bone growth rate $(A)$, mineralizing perimeter $(B)$, mineral apposition rate (C), bone formation rate (D), osteoblast perimeter (E), osteoclast perimeter $(\mathrm{F})$, marrow adiposity $(\mathrm{G})$, adipocyte density $(\mathrm{H})$ and adipocyte size (I) in distal femur metaphysis in female ob/ob mice. Representative photomicrographs illustrating differences in fluorochrome labeling in WT mice treated with vehicle (J), ob/ob mice treated with vehicle $(\mathrm{K})$, ob/ob mice treated with leptin (L) and ob/ob mice treated leptin and ICI (M). Data are mean \pm S.E., $n=5-9 / g r o u p$. aLeptin + ICl treated ob/ob mice different from vehicle-treated WT mice, $P<0.05$; bleptin $+\mathrm{ICl}$ treated ob/ob mice different from vehicle-treated ob/ob mice, $P<0.05 ; \mathrm{cleptin}+\mathrm{ICl}$ treated ob/ob mice different from leptin-treated ob/ob mice, $P<0.05$. Scale bar, $50 \mu \mathrm{m}$.

$\begin{aligned} & \text { http://joe.endocrinology-journals.org } \\ & \text { DOI: } 10.1530 / \mathrm{JOE}-17-0103\end{aligned} \quad$ Printed in Great Britain

Published by Bioscientifica Ltd. 
number, no change in trabecular thickness and lower trabecular spacing.

The effects of treatment on cancellous bone microarchitecture in the 5th lumbar vertebra of $o b / o b$ mice are shown in Table 2. Leptin + ICI treated mice had higher bone volume fraction than WT mice; the higher cancellous bone volume fraction was associated with higher trabecular number, no difference in trabecular thickness and lower trabecular spacing. Leptin + ICI treated mice had lower bone volume fraction than vehicle-treated mice. However, significant differences were not detected between the two groups in any of the architectural endpoints evaluated. Bone volume fraction, connectivity density, trabecular number and trabecular spacing did not differ between leptin + ICI and leptin-treated mice.

The effects of treatment on dynamic bone histomorphometry in distal femur metaphysis of $o b /$ $o b$ mice are shown in Fig. 3A, B, C and D. Leptin + ICI treated mice had higher longitudinal growth rate and mineralizing perimeter than WT mice but significant differences between the two groups were not detected in mineral apposition rate or bone formation rate. Leptin + ICI treated mice had higher values for each of these endpoints than vehicle-treated mice. Leptin+ICI treated mice had higher longitudinal growth rate than leptin-treated mice but mineralizing bone perimeter, mineral apposition rate and bone formation rate did not differ between the two groups.

The effects of treatment on osteoblast perimeter, osteoclast perimeter and MAT in the distal femur metaphysis of ob/ob mice are shown in Fig. 3E, F, G, H and I. Leptin + ICI treated mice had higher osteoblast perimeter, MAT area, adipocyte density and adipocyte size than WT mice but osteoclast perimeter did not differ between the two groups. Leptin + ICI treated mice had higher osteoblast perimeter and lower osteoclast perimeter, MAT area and adipocyte density than vehicletreated mice. Leptin + ICI and leptin-treated mice did not differ in any of the cellular endpoints evaluated. The differences among groups in fluorochrome label and MAT can be readily appreciated in Fig. 3J, K, L and M.

\section{Discussion}

Oestrogens regulate bone growth and turnover and are essential for the sexual dimorphism of the skeleton (Turner et al. 1994). In growing rodents, endogenous estrogens promote termination of longitudinal bone growth, and have bone- and bone compartment-specific effects on bone acquisition and turnover balance (Turner et al. 1992, 1993). ICI is a fluorinated steroid, which binds to estrogen receptors with high affinity and lowers estrogen receptor levels by enhancing their proteosomal degradation (Wakeling \& Bowler 1992, Dauvois et al. 1993). When administered to growing, ovary-intact rodents, ICI, similar to ovx, results in uterine atrophy, increased longitudinal bone growth and cancellous bone loss (Sibonga et al. 1998).

Leptin increases longitudinal bone growth in $o b / o b$ mice (Kishida et al. 2005). The further increase in growth rate in $o b / o b$ mice treated with leptin+ICI provides evidence that the concurrent increase in estrogen levels during leptin treatment antagonizes the growth promoting actions of leptin (Turner et al. 1994). Cancellous bone volume fraction was also higher in the distal femur metaphysis of ICI treated $o b / o b$ mice compared to leptintreated $o b / o b$ mice. This finding was not necessarily anticipated because estrogen deficiency typically results in decreased cancellous bone volume fraction due to reduced trabecular number. However, this positive skeletal effect of ICI on cancellous bone volume fraction was associated with the noted accelerated longitudinal bone growth. Concurrent increases in longitudinal growth and bone formation rates are a plausible explanation for the higher cancellous bone volume fraction in leptin + ICI treated mice. This interpretation is consistent with prior studies demonstrating that sc administration of leptin reduces bone loss in growing ovx rats by attenuating the decrease in trabecular number (Burguera et al. 2001).

Ovx results in a reduction in cortical thickness in mice that is preventable by estrogen replacement (Hawse et al. 2014). In the present study, cortical thickness was increased in hypogonadal $o b / o b$ mice following leptin treatment when compared to untreated $o b / o b$ mice but cortical thickness was not restored to WT levels. Prior studies reported reduced endocortical bone formation in WT mice following adoptive transfer of bone marrow from leptin receptor-deficient $d b / d b$ mice, and increased endocortical bone formation in $o b / o b$ mice following leptin administration (Turner et al. 2013). Thus, the reduced cortical thickness in femurs of $o b / o b$ mice could result from estrogen deficiency, leptin deficiency or combined deficiencies of the two hormones. The absence of an effect of ICI in leptin-treated mice indicates that the resulting increase in cortical thickness does not require estrogen signaling. However, increasing leptin levels while reducing the magnitude did not fully prevent bone loss in ovx rats (Burguera et al. 2001). Taken together, these observations suggest that leptin and estrogen have

Published by Bioscientifica Ltd. 
distinct as well as complementary effects on the skeleton and that both hormones may be required for optimal cortical thickness.

Estrogens play an important role in energy balance. Rodents typically exhibit excess weight gain following ovx due in part to hyperphagia (Clark \& Tarttelin 1982). Pairfeeding ovx rodents to ovary-intact controls attenuates but does not completely prevent excess weight gain, suggesting that ovarian hormones also increase energy expenditure (Jiang et al. 2008). The effects of estrogen on energy balance are believed to occur through estrogen receptormediated signaling within the hypothalamus (Frank et al. 2014). ICI delivered into peripheral circulation may cross the blood-brain barrier and localize in the hypothalamus (Howell et al. 2000, Alfinito et al. 2008). As such, sc administered ICI could antagonize estrogen receptormediated pathways involved in energy metabolism in the central nervous system. In the present study, ICI did not alter the effects of leptin on food consumption or slow weight loss in $o b / o b$ mice. Additionally, hypothalamic leptin gene therapy was shown to be effective in blocking the increase in appetite in rats following ovx (Torto et al. 2006, Ng et al. 2010). These findings suggest that a leptininduced increase in estrogen levels is not required for leptin to suppress appetite. However, the dose rate of ICI used in the present study, although sufficient to block estrogen receptor-mediated actions on uterus and bone (Sibonga et al. 1998), was lower than the concentrations shown to induce hyperphagia and decrease energy expenditure in normal rats (Alfinito et al. 2008). It is therefore possible that higher doses of ICI are required to block the inhibitory actions of leptin-induced estrogen on appetite.

$o b / o b$ mice develop morbid obesity. In contrast to adult WT mice, which were nearly weight stable throughout the one-month duration of our study, $o b / o b$ mice gained weight. As anticipated, leptin treatment resulted in weight loss, which was due in part to lower abdominal WAT weight. We did not measure individual fat depots or lean mass but leptin treatment has been shown to result in a preferential reduction in total fat mass with minimal reduction in water and lean body mass (Rafael \& Herling 2000). Total body weight and abdominal WAT weight, although lower than in untreated $o b / o b$ mice, were still much higher at study termination in leptin-treated $o b / o b$ mice than in WT mice. Similar to appetite, the absence of an effect of co-treatment with leptin and ICI on weight compared to leptin alone suggests that estrogen receptor signaling is largely dispensable for the leptin-mediated reduction in WAT and body weight. This conclusion is concordant with studies demonstrating the efficacy of leptin in preventing weight gain in ovx mice and rats (Torto et al. 2006, da Silva et al. 2014).

Adipose tissue produces a wide array of peptide hormones and cytokines, collectively referred to as adipokines (Ronti et al. 2006). Additionally, adipose tissue expresses aromatase activity and production of estrogens by WAT may contribute to the higher estrogen levels associated with obesity (Cleland et al. 1983, 1985, Magoffin et al. 1999, Liu et al. 2013). Uterine weight, a sensitive index of estrogen level, was positively associated with WAT weight in ob/ob mice (Turner et al. 2014). Leptin treatment increased uterine weight in $o b / o b$ mice (Turner et al. 2014) and this response was blocked by ICI, indicating that ICI treatment was effective in blocking estrogen signaling, regardless of the tissue origin of the hormone.

In spite of drastic differences in abdominal WAT between calorically restricted mice (decreased) and mice with loss of function mutations in the gene for leptin or the gene for leptin receptor (increased), both conditions result in increased MAT (Bartell et al. 2011, Turner \& Iwaniec 2011), a finding implicating leptin as an important negative regulator of MAT. This conclusion is supported by studies demonstrating that increasing leptin levels by sc administration of the hormone, direct delivery of the hormone into the hypothalamus, or by hypothalamic leptin gene therapy reduces MAT in $o b /$ $o b$ mice (Bartell et al. 2011, Turner et al. 2015). However, ovx rats and normal mice fed high fat diet have elevated MAT in spite of elevated leptin levels, and increasing hypothalamic leptin levels does not decrease MAT in normal and ovx rats (Martin \& Zissimos 1991, Iwaniec et al. 2011, Jackson et al. 2011). This paradox is resolved if, similar to appetite and weight gain, the inhibitory effects of high levels of leptin on MAT are impaired by the development of leptin resistance (Sainz et al. 2015). In the present study, the reduction in MAT by sc administration of leptin to leptin-deficient mice was not prevented by co-administration with ICI. Taken together, these findings suggest that estrogen receptor signaling is not required for leptin to reduce MAT levels in $o b / o b$ mice while leptin resistance may facilitate the increase in MAT associated with ovx.

Accurately modeling the diurnal fluctuations observed in serum leptin levels is challenging (Arble et al. 2011). In normal mice, leptin levels display a diurnal rhythm with a nadir in mid-morning and a nocturnal peak (Ahren 2000). In the present study, we administered leptin to leptindeficient $o b / o b$ mice by daily sc injection. This route of

Published by Bioscientifica Ltd 
administration would be expected to result in much greater extremes in maximum and minimum levels of the hormone than occur physiologically. Nevertheless, once daily sc leptin treatment quickly decreased food intake to values similar to WT mice and maintained lower food intake through the remainder of study.

Bone balance is highly sensitive to changes in energy availability (Iwaniec \& Turner 2016). Caloric restriction in adult rats, resulting in only 5\% weight loss, had dramatic negative effects on bone metabolism, including reduced bone formation, increased osteoclast perimeter and reduced cancellous bone volume fraction (Turner \& Iwaniec 2011). In contrast, increases in leptin levels in the hypothalamus of normal rats reduced food intake and body weight without inducing bone loss (Turner et al. 2015). However, a combination of caloric restriction (30\%) and sc leptin treatment, while reducing MAT accumulation, did not prevent the detrimental skeletal changes associated with suppression of normal weight gain in rapidly growing mice (Devlin et al. 2016). These findings suggest that methods that improve leptin signaling have the potential to preserve bone mass during rapid weight loss in adults but are unlikely to compensate for inadequate energy availability during growth.

Adoptive transfer of leptin receptor-deficient $d b /$ $d b$ bone marrow cells into WT mice recapitulated the low bone formation observed in $d b / d b$ mice without increasing food intake (Turner et al. 2013). Additionally, sc infusion of leptin revealed that the stimulatory effects of leptin on bone formation occur at leptin levels that have minimal effects on energy metabolism (Philbrick et al. 2017). These findings provide strong evidence that leptin acts peripherally to stimulate bone formation. However, the putative target cells in bone and precise mechanisms mediating the bone anabolic effects of leptin in $o b / o b$ mice have not been identified.

It is likely that some of the profound abnormalities in bone metabolism in leptin-deficient $o b / o b$ mice occur as a result of comorbidities and hormonal changes. Comorbidities include hypogonadism, hyperphagia, impaired thermoregulation and hyperglycemia. Alterations in bone regulating hormones and growth factors include increased corticosteroid levels, and low levels of sex steroids, growth hormone and IGF1 (Saito \& Bray 1983, Ozata et al. 1999, Segev et al. 2007, Turner et al. 2014). Additionally, hyperparathyroidism is associated with leptin deficiency in humans (Ozata et al. 1999). In the present study, we demonstrate that ovarian hormones play a limited role in mediating the skeletal actions of leptin. In prior studies, we showed that hyperphagia, hyperglycemia and impaired thermoregulation, typically observed in $o b / o b$ mice, actually attenuate skeletal abnormalities in these animals (Turner et al. 2014). Taken together, these findings indicate that leptin plays an important role in regulating bone growth, maturation and turnover but further research is required to understand the full range of actions by the hormone.

In summary, the profound abnormalities in metabolism in $o b / o b$ mice, including hyperphagia and morbid obesity were attenuated or reversed following combination treatment with leptin and the estrogen receptor antagonist ICI. Similarly, leptin+ICI re-established compensatory increases in bone growth and near normal bone turnover, without restoring normal uterine weight. The increase in osteoblast-lined bone perimeter and bone formation in leptin + ICI treated $o b / o b$ mice was accompanied by a reduction in MAT, suggesting that treatment promoted the differentiation of stromal cells to osteoblasts at the expense of adipocytes. Finally, the limited differences in skeletal endpoints between $o b / o b$ mice treated with leptin compared to $o b / o b$ mice treated with leptin+ICI indicate that estrogen receptor signaling is dispensable for the positive actions of leptin on bone and that estrogen may attenuate leptin-induced bone growth.

Declaration of interest

The authors declare that there is no conflict of interest that could be perceived as prejudicing the impartiality of the research reported.

\section{Funding}

This work was supported by grants from the NIH (AR060913), NASA (NNX12AL24G) and USDA (38420-17804).

\section{Author contribution statement}

Study design was done by R T T, K A P, A J B and U T I. Study execution was done by K A P. Data collection was done by K A P, A K and R T T. Data analysis was done by A J B. Data interpretation was done by R T T, K A P, $A J B$ and $U$ T I. Drafting of manuscript was done by R T T and U T I. Revising manuscript content was done by K A P, A J B, R T T and U T I. Approval of the final version of manuscript was done by $R T T, K A P, A K, A J B$ and U T I. U T I takes responsibility for the integrity of the data.

\section{References}

Ahima RS, Dushay J, Flier SN, Prabakaran D \& Flier JS 1997 Leptin accelerates the onset of puberty in normal female mice. Journal of Clinical Investigation 99 391-395. (doi:10.1172/JCI119172)

Published by Bioscientifica Ltd 
Ahren B 2000 Diurnal variation in circulating leptin is dependent on gender, food intake and circulating insulin in mice. Acta Physiologica Scandinavica 169 325-331. (doi:10.1046/j.1365-201x.2000.00746.x)

Alfinito PD, Chen X, Atherton J, Cosmi S \& Deecher DC 2008 ICI 182,780 penetrates brain and hypothalamic tissue and has functiona effects in the brain after systemic dosing. Endocrinology 149 5219-5226. (doi:10.1210/en.2008-0532)

Arble DM, Vitaterna MH \& Turek FW 2011 Rhythmic leptin is required for weight gain from circadian desynchronized feeding in the mouse. PLoS ONE 6 e25079. (doi:10.1371/journal.pone.0025079)

Barash IA, Cheung CC, Weigle DS, Ren H, Kabigting EB, Kuijper JL, Clifton DK \& Steiner RA 1996 Leptin is a metabolic signal to the reproductive system. Endocrinology 137 3144-3147. (doi:10.1210/ en.137.7.3144)

Bartell SM, Rayalam S, Ambati S, Gaddam DR, Hartzell DL, Hamrick M, She JX, Della-Fera MA \& Baile CA 2011 Central (ICV) leptin injection increases bone formation, bone mineral density, muscle mass, serum IGF-1, and the expression of osteogenic genes in leptin-deficient ob/ob mice. Journal of Bone and Mineral Research 26 1710-1720. (doi:10.1002/jbmr.406)

Burguera B, Hofbauer LC, Thomas T, Gori F, Evans GL, Khosla S, Riggs BL \& Turner RT 2001 Leptin reduces ovariectomy-induced bone loss in rats. Endocrinology 142 3546-3553. (doi:10.1210/endo.142.8.8346)

Clark RG \& Tarttelin MF 1982 Some effects of ovariectomy and estrogen replacement on body composition in the rat. Physiology and Behavior 28 963-969. (doi:10.1016/0031-9384(82)90161-5)

Cleland WH, Mendelson CR \& Simpson ER 1983 Aromatase activity of membrane fractions of human adipose tissue stromal cells and adipocytes. Endocrinology 113 2155-2160. (doi:10.1210/endo-113-62155)

Cleland WH, Mendelson CR \& Simpson ER 1985 Effects of aging and obesity on aromatase activity of human adipose cells. Journal of Clinical Endocrinology and Metabolism 60 174-177. (doi:10.1210/jcem60-1-174)

da Silva RP, Zampieri TT, Pedroso JA, Nagaishi VS, Ramos-Lobo AM, Furigo IC, Camara NO, Frazao R \& Donato J Jr 2014 Leptin resistance is not the primary cause of weight gain associated with reduced sex hormone levels in female mice. Endocrinology 155 4226-4236. (doi:10.1210/en.2014-1276)

Dauvois S, White R \& Parker MG 1993 The antiestrogen ICI 182780 disrupts estrogen receptor nucleocytoplasmic shuttling. Journal of Cell Science 106 1377-1388.

Dempster DW, Compston JE, Drezner MK, Glorieux FH, Kanis JA, Malluche H, Meunier PJ, Ott SM, Recker RR \& Parfitt AM 2013 Standardized nomenclature, symbols, and units for bone histomorphometry: a 2012 update of the report of the ASBMR Histomorphometry Nomenclature Committee. Journal of Bone and Mineral Research 28 2-17. (doi:10.1002/jbmr.1805)

Devlin MJ, Brooks DJ, Conlon C, Vliet M, Louis L, Rosen CJ \& Bouxsein ML 2016 Daily leptin blunts marrow fat but does not impact bone mass in calorie-restricted mice. Journal of Endocrinology 229 295-306. (doi:10.1530/JOE-15-0473)

Frank A, Brown LM \& Clegg DJ 2014 The role of hypothalamic estrogen receptors in metabolic regulation. Frontiers in Neuroendocrinology 35 550-557. (doi:10.1016/j.yfrne.2014.05.002)

Hamrick MW, Della-Fera MA, Choi YH, Pennington C, Hartzell D \& Baile CA 2005 Leptin treatment induces loss of bone marrow adipocytes and increases bone formation in leptin-deficient ob/ob mice. Journal of Bone and Mineral Research 20 994-1001. (doi:10.1359/JBMR.050103)

Hawse JR, Pitel KS, Cicek M, Philbrick KA, Gingery A, Peters KD, Syed FA, Ingle JN, Suman VJ, Iwaniec UT et al. 2014 TGFbeta inducible early gene-1 plays an important role in mediating estrogen signaling in the skeleton. Journal of Bone and Mineral Research 29 1206-1216. (doi:10.1002/jbmr.2142)

Holm S 1979 A simple sequentially rejective multiple test procedure. Scandinavian Journal of Statistics $\mathbf{6} 65-70$.
Howell A, Osborne CK, Morris C \& Wakeling AE 2000 ICI 182,780 (Faslodex): development of a novel, 'pure' antiestrogen. Cancer 89 817-825. (doi:10.1002/1097-0142(20000815)89:4<817::AIDCNCR14>3.0.CO;2-6)

Iwaniec UT \& Turner RT 2016 Influence of body weight on bone mass, architecture and turnover. Journal of Endocrinology 230 R115-R130. (doi:10.1530/JOE-16-0089)

Iwaniec UT, Boghossian S, Lapke PD, Turner RT \& Kalra SP 2007 Central leptin gene therapy corrects skeletal abnormalities in leptin-deficient ob/ob mice. Peptides 28 1012-1019. (doi:10.1016/j. peptides.2007.02.001)

Iwaniec UT, Wronski TJ \& Turner RT 2008 Histological analysis of bone. Methods in Molecular Biology 447 325-341. (doi:10.1007/978-1-59745242-7_21)

Iwaniec UT, Boghossian S, Trevisiol CH, Wronski TJ, Turner RT \& Kalra SP 2011 Hypothalamic leptin gene therapy prevents weight gain without long-term detrimental effects on bone in growing and skeletally mature female rats. Journal of Bone and Mineral Research 26 1506-1516. (doi:10.1002/jbmr.365)

Iwaniec UT, Philbrick KA, Wong CP, Gordon JL, Kahler-Quesada AM, Olson DA, Branscum AJ, Sargent JL, DeMambro VE, Rosen CJ et al. 2016 Room temperature housing results in premature cancellous bone loss in growing female mice: implications for the mouse as a preclinical model for age-related bone loss. Osteoporosis International 27 3091-3101. (doi:10.1007/s00198-016-3634-3)

Jackson MA, Iwaniec UT, Turner RT, Wronski TJ \& Kalra SP 2011 Effects of increased hypothalamic leptin gene expression on ovariectomyinduced bone loss in rats. Peptides 32 1575-1580. (doi:10.1016/j. peptides.2011.04.029)

Jiang JM, Sacco SM \& Ward WE 2008 Ovariectomy-induced hyperphagia does not modulate bone mineral density or bone strength in rats. Journal of Nutrition 138 2106-2110. (doi:10.3945/jn.108.093781)

Jing D, Luo E, Cai J, Tong S, Zhai M, Shen G, Wang X \& Luo Z 2016 Mechanical vibration mitigates the decrease of bone quantity and bone quality of leptin receptor-deficient $\mathrm{db} / \mathrm{db}$ mice by promoting bone formation and inhibiting bone resorption. Journal of Bone and Mineral Research 31 1713-1724. (doi:10.1002/jbmr.2837)

Kishida Y, Hirao M, Tamai N, Nampei A, Fujimoto T, Nakase T, Shimizu $\mathrm{N}$, Yoshikawa H \& Myoui A 2005 Leptin regulates chondrocyte differentiation and matrix maturation during endochondral ossification. Bone 37 607-621. (doi:10.1016/j.bone.2005.05.009)

Kume K, Satomura K, Nishisho S, Kitaoka E, Yamanouchi K, Tobiume S \& Nagayama M 2002 Potential role of leptin in endochondral ossification. Journal of Histochemistry and Cytochemistry 50 159-169. (doi:10.1177/002215540205000204)

Liu E, Samad F \& Mueller BM 2013 Local adipocytes enable estrogendependent breast cancer growth: role of leptin and aromatase. Adipocyte 2 165-169. (doi:10.4161/adip.23645)

Magoffin DA, Weitsman SR, Aagarwal SK \& Jakimiuk AJ 1999 Leptin regulation of aromatase activity in adipose stromal cells from regularly cycling women. Ginekologia Polska 70 1-7.

Mantzoros CS, Magkos F, Brinkoetter M, Sienkiewicz E, Dardeno TA, Kim SY, Hamnvik OP \& Koniaris A 2011 Leptin in human physiology and pathophysiology. American Journal of Physiology: Endocrinology and Metabolism 301 E567-E584. (doi:10.1152/ajpendo.00315.2011)

Maor G, Rochwerger M, Segev Y \& Phillip M 2002 Leptin acts as a growth factor on the chondrocytes of skeletal growth centers. Journal of Bone and Mineral Research 17 1034-1043. (doi:10.1359/ jbmr.2002.17.6.1034)

Martin RB \& Zissimos SL 1991 Relationships between marrow fat and bone turnover in ovariectomized and intact rats. Bone 12 123-131. (doi:10.1016/8756-3282(91)90011-7)

Ng KY, Yong J \& Chakraborty TR 2010 Estrous cycle in ob/ob and ovariectomized female mice and its relation with estrogen and leptin. Physiology and Behavior 99 125-130. (doi:10.1016/j. physbeh.2009.11.003) 
Ozata M, Ozdemir IC \& Licinio J 1999 Human leptin deficiency caused by a missense mutation: multiple endocrine defects, decreased sympathetic tone, and immune system dysfunction indicate new targets for leptin action, greater central than peripheral resistance to the effects of leptin, and spontaneous correction of leptin-mediated defects. Journal of Clinical Endocrinology and Metabolism 84 3686-3695. (doi:10.1210/jcem.84.10.5999)

Philbrick KA, Wong CP, Branscum AJ, Turner RT \& Iwaniec UT 2017 Leptin stimulates bone formation in ob/ob mice at doses having minimal impact on energy metabolism. Journal of Endocrinology 232 461-474. (doi:10.1530/JOE-16-0484)

Rafael J \& Herling AW 2000 Leptin effect in ob/ob mice under thermoneutral conditions depends not necessarily on central satiation. American Journal of Physiology: Regulatory, Integrative and Comparative Physiology 278 R790-R795.

Ronti T, Lupattelli G \& Mannarino E 2006 The endocrine function of adipose tissue: an update. Clinical Endocrinology 64 355-365. (doi:10.1111/j.1365-2265.2006.02474.x)

Sainz N, Barrenetxe J, Moreno-Aliaga MJ \& Martinez JA 2015 Leptin resistance and diet-induced obesity: central and peripheral actions of leptin. Metabolism 64 35-46. (doi:10.1016/j.metabol.2014.10.015)

Saito M \& Bray GA 1983 Diurnal rhythm for corticosterone in obese (ob/ ob) diabetes $(\mathrm{db} / \mathrm{db})$ and gold-thioglucose-induced obesity in mice. Endocrinology 113 2181-2185. (doi:10.1210/endo-113-6-2181)

Segev Y, Eshet R, Yakir O, Haim N, Phillip M \& Landau D 2007 Systemic and renal growth hormone-IGF1 axis involvement in a mouse model of type 2 diabetes. Diabetologia 50 1327-1334. (doi:10.1007/s00125007-0663-7)

Sibonga JD, Dobnig H, Harden RM \& Turner RT 1998 Effect of the high-affinity estrogen receptor ligand ICI 182,780 on the rat tibia. Endocrinology 139 3736-3742. (doi:10.1210/en.139.9.3736)

R Core Team RC 2015 R: A Language and Environment for Statistical Computing. Vienna, Austria: R Foundation for Statistical Computing.

Torto R, Boghossian S, Dube MG, Kalra PS \& Kalra SP 2006 Central leptin gene therapy blocks ovariectomy-induced adiposity. Obesity 14 1312-1319. (doi:10.1038/oby.2006.149)
Turner RT \& Iwaniec UT 2011 Low dose parathyroid hormone maintains normal bone formation in adult male rats during rapid weight loss. Bone 48 726-732. (doi:10.1016/j.bone.2010.12.034)

Turner RT, Backup P, Sherman PJ, Hill E, Evans GL \& Spelsberg TC 1992 Mechanism of action of estrogen on intramembranous bone formation: regulation of osteoblast differentiation and activity. Endocrinology 131 883-889. (doi:10.1210/en.131.2.883)

Turner RT, Evans GL \& Wakley GK 1993 Mechanism of action of estrogen on cancellous bone balance in tibiae of ovariectomized growing rats: inhibition of indices of formation and resorption. Journal of Bone and Mineral Research 8 359-366. (doi:10.1002/ jbmr.5650080313)

Turner RT, Riggs BL \& Spelsberg TC 1994 Skeletal effects of estrogen. Endocrine Reviews 15 275-300. (doi:10.1210/er.15.3.275)

Turner RT, Kalra SP, Wong CP, Philbrick KA, Lindenmaier LB, Boghossian S \& Iwaniec UT 2013 Peripheral leptin regulates bone formation. Journal of Bone and Mineral Research 28 22-34. (doi:10.1002/ jbmr.1734)

Turner RT, Philbrick KA, Wong CP, Olson DA, Branscum AJ \& Iwaniec UT 2014 Morbid obesity attenuates the skeletal abnormalities associated with leptin deficiency in mice. Journal of Endocrinology 223 M1-M15. (doi:10.1530/JOE-14-0224)

Turner RT, Dube M, Branscum AJ, Wong CP, Olson DA, Zhong X, Kweh MF, Larkin IV, Wronski TJ, Rosen CJ, et al. 2015 Hypothalamic leptin gene therapy reduces body weight without accelerating age-related bone loss. Journal of Endocrinology 227 129-141. (doi:10.1530/JOE-150280)

Wakeling AE \& Bowler J 1992 ICI 182,780, a new antiestrogen with clinical potential. Journal of Steroid Biochemistry and Molecular Biology 43 173-177. (doi:10.1016/0960-0760(92)90204-V)

Welch B 1951 On the comparison of several mean values: an alternative approach. Biometrika 38 330-336. (doi:10.1093/biomet/38.3-4.330)

Williams GA, Callon KE, Watson M, Costa JL, Ding Y, Dickinson M, Wang Y, Naot D, Reid IR \& Cornish J 2011 Skeletal phenotype of the leptin receptor-deficient $\mathrm{db} / \mathrm{db}$ mouse. Journal of Bone and Mineral Research 26 1698-1709. (doi:10.1002/jbmr.367)

Received in final form 30 March 2017

Accepted 19 April 2017

Accepted Preprint published online 19 April 2017 (c) 2017 Society for Endocrinology Printed in Great Britain 